\title{
Media and Health Information Literacy among Senior Citizens in Iceland
}

\author{
Ágústa Pálsdóttir \\ Professor, PhD \\ University of Iceland, Information Science Department \\ E-mail agustap@hi.is
}

Competency in media and health information literacy (MHIL) is important as a tool for lifelong learning, which provides people with opportunities to make informed decisions about healthy living. In order to improve knowledge about how senior citizens lifelong learning can be supported, the study investigated various aspects of MHIL among seniors: motivation, information seeking behaviour and evaluation of information in the Media, from Health specialists and on the Internet. A random sample was used and data collected in 2012. Participants were categorized into two groups, 60 to 67 years and 68 years or older. Data analysis was performed with ANOVA (one-way). The findings suggest that the age groups have more in common than what differentiates them. They are equally motivated, have the same preferences for information seeking and information channels, and hold the same beliefs about information quality. The main differences were that the younger group sought information somewhat more frequently, and the older group was more critical of information quality.

Keywords: lifelong learning; media and health information literacy; senior citizens; Iceland

\section{Introduction}

The proportion of senior citizens in the world population is growing rapidly. It is expected that from 2013 to 2050 the number of people aged 60 years and older will more than double globally (United Nations, 2013). In Western countries the predictions are slightly lower, with the proportion of senior citizens forecasted to double, from 11\% in 2006 to $22 \%$ in 2050 (World Health Organization, 2007, p. 3).

This major demographic shift poses challenges and a need to prepare for the increasing number of senior citizens. It is important to advance their prospects of enjoying independence for as long as possible and to ensure their wellness and quality of life. It involves promoting their possibilities to manage their everyday life affairs, as well as their opportunities to participate in the community and continue to contribute to it. Inspiring them to stay healthy for as long as possible is essential, for both the individuals and society, as it is likely to support their independence.

\subsection{Lifelong learning about healthy lifestyle}

It is of major importance for seniors to take an active part in health promotion and to practice a healthy lifestyle. As a prerequisite, it is not only necessary for them to possess knowledge about healthy behaviour, they need to maintain their understanding of healthy living by adding new information to their current level of knowledge.

The term health literacy is important in this context. According to World Health Organization (1998), health literacy stands for „the cognitive and social skills which determine the motivation and ability of individuals to gain access to, understand and use information in ways which promote and maintain good health (p. 10)." In addition, the Medical Library Association's (MLA) has

Revista Română de Biblioteconomie şi Ştiința Informării = Romanian Journal of Library and Information Science ISSN 2559-5490, ISSN-L 1841-1940 • Volume 13 Issue 32017 pp. 59-74 https://doi.org/10.26660/rrbsi.2017.13.3.59

This work is licensed under a Creative Commons Attribution-NonCommercial-NoDerivatives 4.0 International License 
defined health information literacy as "the set of abilities needed to: recognize a health information need; identify likely information sources and use them to retrieve relevant information; assess the quality of the information and its applicability to a specific situation; and analyze, understand, and use the information to make good health decisions" (Niemelä et al., 2012; Schardt, 2011). These concepts are closely related to a joint definition by UNESCO and IFLA (International Federation of Library and Information Association) of Media and Information Literacy, which allows individuals to "...access, retrieve, understand, evaluate and use, create, as well as share information and media content in all formats..." (UNESCO, 2014). The term Media and Health Information Literacy (MHIL) is used in this paper, as it combines the concepts discussed above.

Competency in MHIL is important as a tool for lifelong learning, which provides people with better opportunities to make informed health decisions. Furthermore, there are indications about a positive connection between healthy behaviour and MHIL (Enwald et al., 2016, p. 352; Pálsdóttir, 2008). Possessing these competences can provide senior citizens with more confidence and strengths that may support them at remaining healthy, independent and active members of society. It is, therefore, important that libraries and information specialists take a leadership role at enhancing their MHIL and thereby their opportunities for healthy living.

The key elements of MHIL is that people possess the motivation and the personal skills that allow them to acquire information and draw knowledge from it (National Institutes of Health, 2016; World Health Organization, 1998). The need to pay more attention to motivation, especially how interest in a topic may act as a driving force that inspires people to seek health information, has been stressed in several studies (Pálsdóttir, 2008; Savolainen, 2015, p. 616).

Access to quality information appropriate to seniors needs, which can be sought through the preferred information channels, is furthermore of significance for their lifelong learning. Information seeking has commonly been described as a goal-driven and purposeful activity (see, for example Johnson and Meischke, 1993, p. 343-344; Wilson, 2000, p. 49). However, it has been pointed out that the nature of information seeking behaviour is more complex than this, and that people often happen to come across information without having intended to seek it. This has been variously termed as opportunistic acquisition of information (Erdelez, 1997, p. 218-219), serendipity (Foster and Ford, 2003, p. 338; Toms, 2000), non-directed monitoring and information seeking by proxy (McKenzie, 2003, 26), or passive attention (Wilson, 2000, p. 53). In two separate population surveys in Iceland (2002 and 2007), Pálsdóttir (2010, p. 240) studied the relation between purposive seeking of health information and opportunistic discovery. The results support that finding information unexpectedly is an integral feature of information seeking behaviour, and that people find information by chance more often than they seek it on purpose. Together these two styles formed a pattern of information seeking behaviour, showing that those seeking health information more often on purpose also find it more often by chance, and vice versa.

Another important factor of MHIL is the evaluation of information quality. It has, for example, been noted that attitude towards information sources, such as the ideas that people have about reliability and usefulness, may influence the use (Buttriss, 1997, p. 1987). Findings from several studies indicate that people tend to rate the reliability of information on the internet lower than information in other channels (Hesse et al., 2005, p. 2620; Pálsdóttir, 2011; Soederberg Miller and Bell, 2012, p. 534). Because health information is increasingly being disseminated digitally this is of concern, particularly for senior citizens who have been later to adopt the use of internet sources than those who are younger (Smith, 2014; Pálsdóttir, 2011; Statistics Iceland, 2012). It is therefore vital to enhance their MHIL by guiding them as to where quality health information can be accessed on the internet, as well as how the quality of the information can be evaluated. Otherwise, they may be cut off from using digital information to make rational decisions about their health related behaviour. 


\subsection{Aim and research questions}

The aim of the current study is to investigated certain aspects of MHIL among Icelanders who are 60 years or older with the purpose of improving knowledge about seniors can be supported at lifelong learning about healthy lifestyle.

The possibilities of senior citizens to improve their knowledge in order to make informed choices that promote health and wellbeing is a crucial issue. It may have impact on their wider prospects for remaining strongly connected to the community and on their quality of life. Yet, a number of questions about their skills at MHIL remain unanswered. Identifying some of the factors related to this may open opportunities to support and strengthen their skills. Subsequently, the capacity of seniors to seek information and knowledge can be enhanced.

It has been traditional in western countries to use the retirement age to define senior citizens (Thane, 1989, p. 94). In Iceland elderly is defined by law as people who have reached the age of 67 (Lög um málefni aldraðra nr. 125/1999), when it is usual for people to retire. This has, however, been criticised for not taking into consideration the heterogeneity of senior citizens. It has been pointed out that people's chronological age is less important than their physical, cognitive and social capabilities (Ries and Pöthiga, 1984, p. 112). In Iceland it is customary and preferred by older adults to use the term senior citizens and therefore it is used in this study. Furthermore, in accordance with the viewpoints that there is no clearly defined age when people become seniors, the associations for senior citizens in Iceland admit those who have reached the age of 60 to become members.

Classifying all seniors together in one age category may obscure differences among them, while comparing sub-groups can generate differences and similarities between them. In view of the above, it was decided that people who have reached the age of 60 should be included in the study, and that those who are at the age 60 to 67 years, a group who is approaching retirement, should be compared with people aged 68 years or older, who have reached the retirement age. In addition, it was decided to examine the effects of sex and education on their MHIL.

The focus of recent studies has mainly been on how seniors have adopted to the digitalization of health information. Although this is an important aspect, the information environment that people live in is more divers and complex. It includes not only digital information but rather information in various formats, which can be accessed in different ways. The present study aims at gaining a more holistic picture by examining senior citizens MHIL within a broad network of information sources and channels, which can be accessed by different means of information seeking methods. The paper will seek answers to the following questions:

1. Do the age groups 60-67 years old and 68 years or older differ in:

a) Motivation to seek knowledge about healthy lifestyle?

b) Information seeking behaviour?

c) Evaluation of information?

2. Do the age groups 60 to 67 years old and 68 years or older differ in their motivation, information seeking and evaluation of information, by sex and/or education?

\section{Methods}

The data were gathered in spring 2012, using an internet and a telephone survey from two random samples of 600 people each, aged 18 years and older from the whole country. The datasets were merged, allowing answers from all individuals belonging to each set of data. The total response rate was $58.4 \%$. The current study involves only participants who are 60 years and older. A total of 176 people participated in the study, 86 women and 90 men. Participants aged 60 to 67 years were 87 while 89 participants were 68 years or older. 


\subsection{Measurements and data analysis}

The following measurements were used in the study:

(1) Socio-demographic information included traditional background variables: sex, age, education, marital status, residence and income. Based on previous analysis the variables sex and education are used in the current study. Education was measured as the highest level of education completed. Three levels were distinguished: 1) primary education, those who have finished compulsory education; 2) secondary education, those who have completed vocational training or secondary school; 3) university education.

(2) Age groups. To assess how MHIL relates to age, the participants were divided into two groups, people aged 60 to 67 years and those who are 68 years and older.

(3) Motivation was assessed by asking two questions: 'How interested are you in information about health and lifestyle'?, and 'Do you talk about health and lifestyle with others'? Both questions contained a 5-point response scale (5: Very interested/Very often - 1: No interest at all/Never).

(4) Information seeking. Based on a review of the literature, it is assumed that information seeking can be broadly divided into two information-seeking styles. Purposive information seeking was examined by asking: 'Have you sought information about health and lifestyle in any of the following sources'? Opportunistic discovery of information was examined by asking: "Have you come across information about health and lifestyle in any of the following sources although you were not seeking the information"? A list of 25 information sources was presented at each question. A five-point response scale was used (5: Very often - 1: Never).

(5) Quality of information. This was examined by two questions: 'How useful do you find information about health and lifestyle in the following sources'?, and 'How reliable do you find information about health and lifestyle in the following sources'? The questions had a five-point response scale (5: Very useful/reliable - 1: Don't know). The same list of information sources was presented at both questions as at the questions about information seeking.

Factor analysis was used to extract latent factors on the questions about purposive seeking, opportunistic discovery of information and evaluation of usefulness and reliability of information, in the data. The Principal Component Factoring method of extraction was employed to examine the factor structure of each question. In all cases, the criteria for factor loadings were set above 0.3 , and oblique rotation (Oblimin) was adopted in all the analyses. For all the analyses, multiple criteria, based on eigenvalue $>1.00$, a screen test and conceptual interpretability of the factor structure, suggested that extracting three factors would be adequate. The factors were named: Media, Health specialists and Internet. The Media contains information in television, radio and printed newspapers, Health specialists contains information in print from health specialists, as well as discussions with specialists of the health professions. The Internet contains all digital information, including websites by the health care system or health specialists and information in social media.

The factors explained $72.3 \%$ of the total variance in the data for purposive information seeking, $72.0 \%$ for opportunistic discovery of information, $74.6 \%$ for usability and $69.5 \%$ for reliability of information. The scales were checked for internal reliability and Cronbach's alpha ranged from 0.87 to 0.90 for purposive seeking, 0.90 to 0.95 for opportunistic discovery of information, from 0.87 to 0.92 for usefulness of information and for reliability of information from 0.86 to 0.91 .

ANOVA (one-way) was performed to examine difference across the age groups, as well as the effects of sex and education, and how it interacts on the age groups motivation, information seeking and evaluation of information. 


\section{Results}

Results about the motivation for seeking knowledge about healthy lifestyle are presented first. After that, results about information seeking behaviour in the channels Media, Health specialists and Internet, will be introduced. Finally, results about the evaluation of the usefulness and reliability of information in the same channels will be presented. All results are presented as mean figures.

\subsection{Motivation to seek knowledge about healthy lifestyle}

Motivation to seek knowledge about healthy living was measured by two variables, participants' interest in information about the topic and how often they discussed it with others.

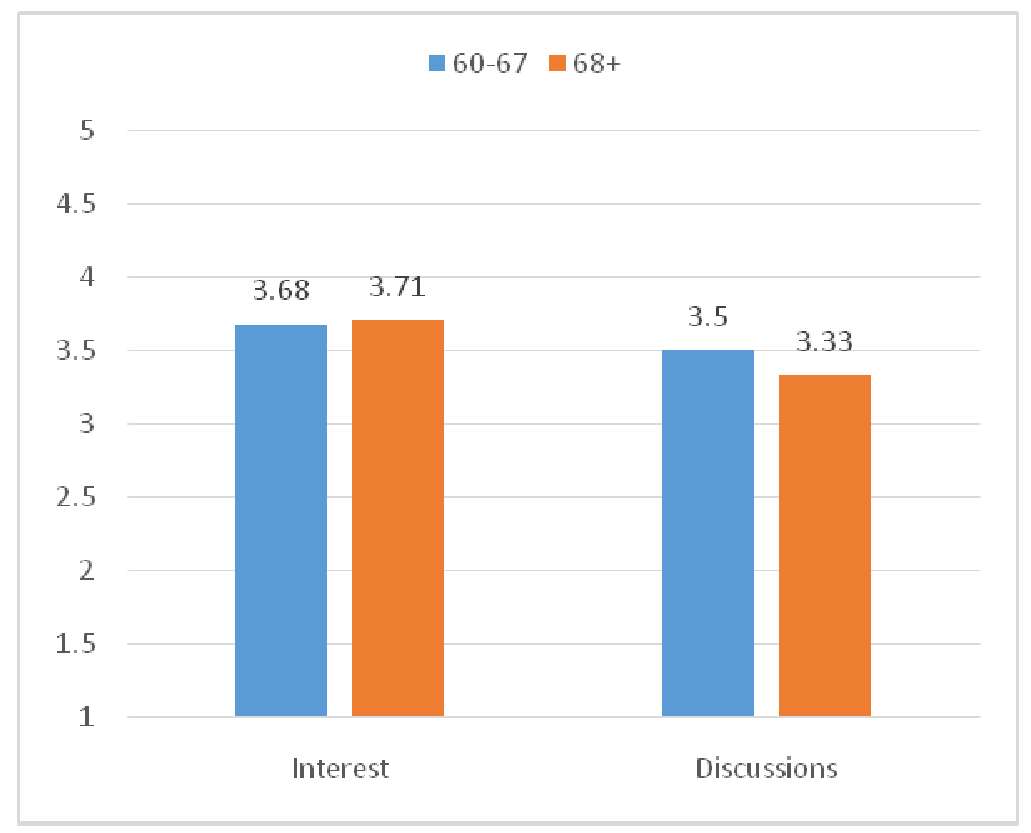

Figure 1. Motivation to seek knowledge about healthy lifestyle - Difference by age

As can be seen from Figure 1 motivation is very similar across the age groups and above medium (3). When the participants interest for information about healthy living $F(1,190=0,97 ; p=0,793)$ and how often they discussed the topic with others $\mathrm{F}(1,189=1,55 ; \mathrm{p}=0,215)$ was examined, no significant difference was found across the age groups.

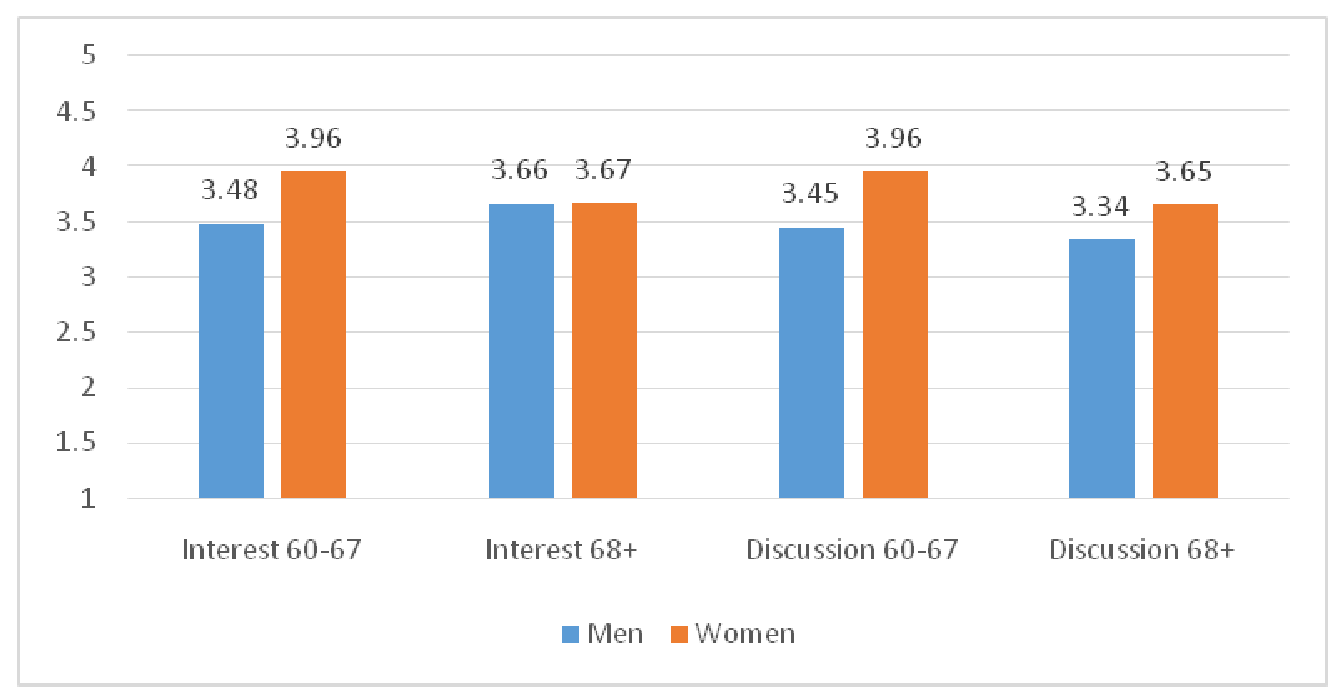

Figure 2. Motivation to seek knowledge about healthy lifestyle-Difference by sex and age 
Figure 2 shows that women in the younger age group were somewhat more interested in information than men, however, the difference was not significant $F(1,95=0,01 ; p=0,934)$. In the age group 68 years and older there was not a difference by sex $F(1,92=0,27 ; p=0,605)$. Furthermore, women in both the younger $\mathrm{F}(1,94=3,08 ; \mathrm{p}=0,083)$ and the older group $\mathrm{F}(1,92=1,14$; $\mathrm{p}=0,288$ ) discussed the topic of healthy living more frequently than men, but the difference was not significant.

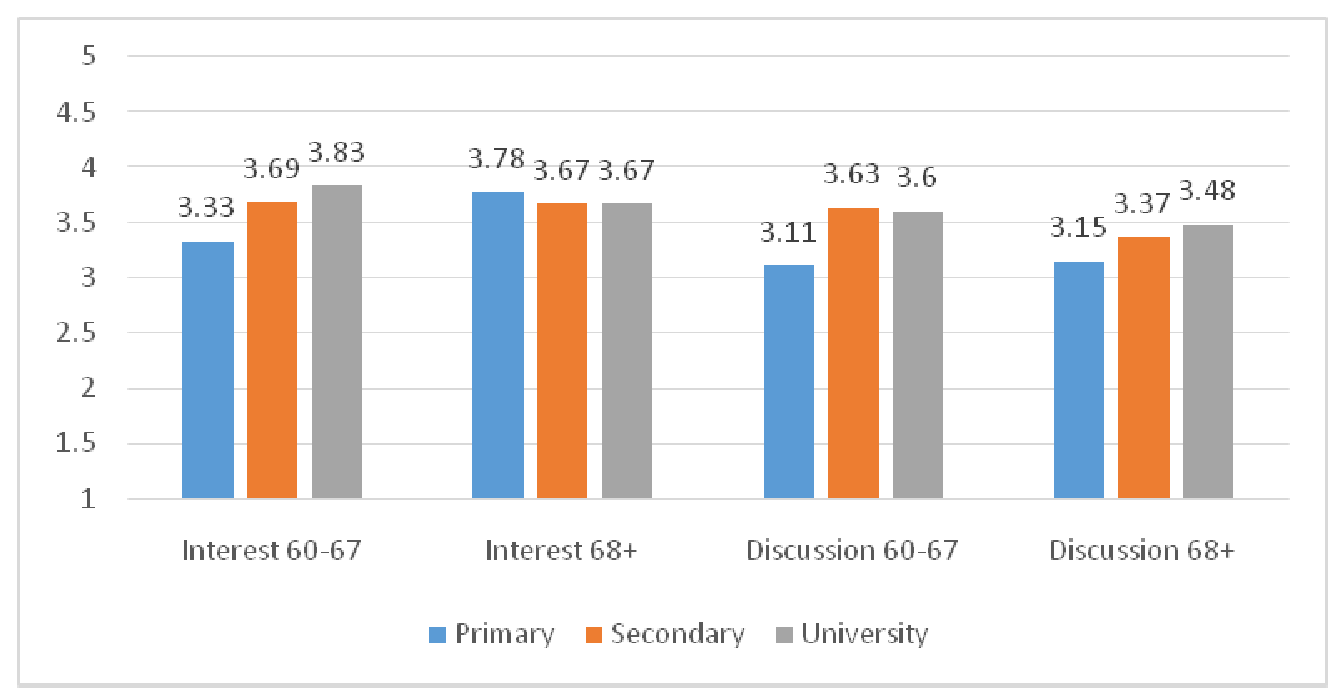

Figure 3. Motivation to seek knowledge about healthy lifestyle - Difference by education and age

Participants with primary education in the younger group were least interested in information about healthy lifestyle while those with university education were most interested. However, the difference was not significant, $\mathrm{F}(2,86=2,48 ; \mathrm{p}=0,089)$. In the older group, the mean figures were almost identical for each educational group and no significant difference was detected $\mathrm{F}$ $(2,88=0,14 ; \mathrm{p}=0,872)$. Results about discussions revealed that, in both the younger $\mathrm{F}(2,85=2,26$; $\mathrm{p}=0,11)$ and the older group $\mathrm{F}(2,88=0,7 ; \mathrm{p}=0,498)$, participants with primary education talked less often with others about this topic than those with secondary and university education, but the difference was not significant (see Figure 3).

\subsection{Information seeking}

Information seeking was investigated by examining both purposive seeking and opportunistic discovery of information, in the channels Media, Health specialists and Internet. Results about difference by age groups for each information seeking style will be introduced first. This will be followed by results about the effects of sex and education on purposive seeking and after that on opportunistic discovery.

As Figure 4 shows, both age groups sought information on purpose and discovered it opportunistically most often in Media and least often on the Internet. A comparison, revealed that information were discovered opportunistically more often than it was sought on purpose, in all information channels. The only exception was information seeking on the Internet by the older age group.

In addition, those aged 68 years and older sought information somewhat less often than those who are aged 60 to 67 years, in all channels. Nevertheless, the difference across the age groups for purposive seeking was very small and not significant (Media $F(1,170=0,65 ; p=0,42$ ), Health specialists $\mathrm{F}(1,178=0,89 ; \mathrm{p}=0,347)$, Internet $\mathrm{F}(1,179=1,74 ; \mathrm{p}=0,189)$. Likewise, results about opportunistic information discovery in the Media revealed that the difference across the age groups was small and not significant $\mathrm{F}(1,169=1,55 ; \mathrm{p}=0,215)$. However, the younger age group 
discovered information significantly more often than the older group from Health specialists $\mathrm{F}$ $(1,169=6,27 ; p=0,013)$ and on the Internet $F(1,162=6,94 ; p=0,009)$.

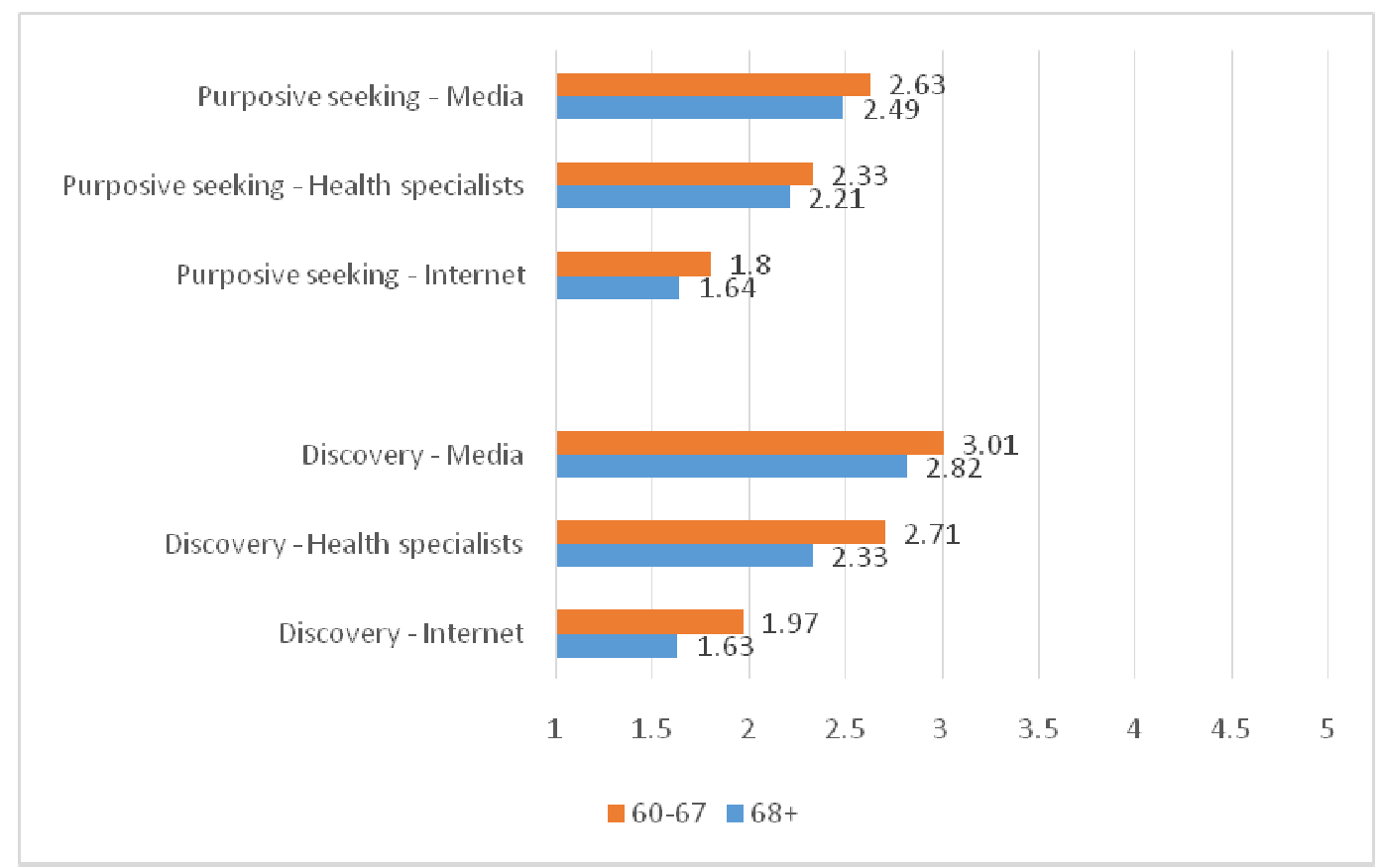

Figure 4. Information seeking - Difference by age

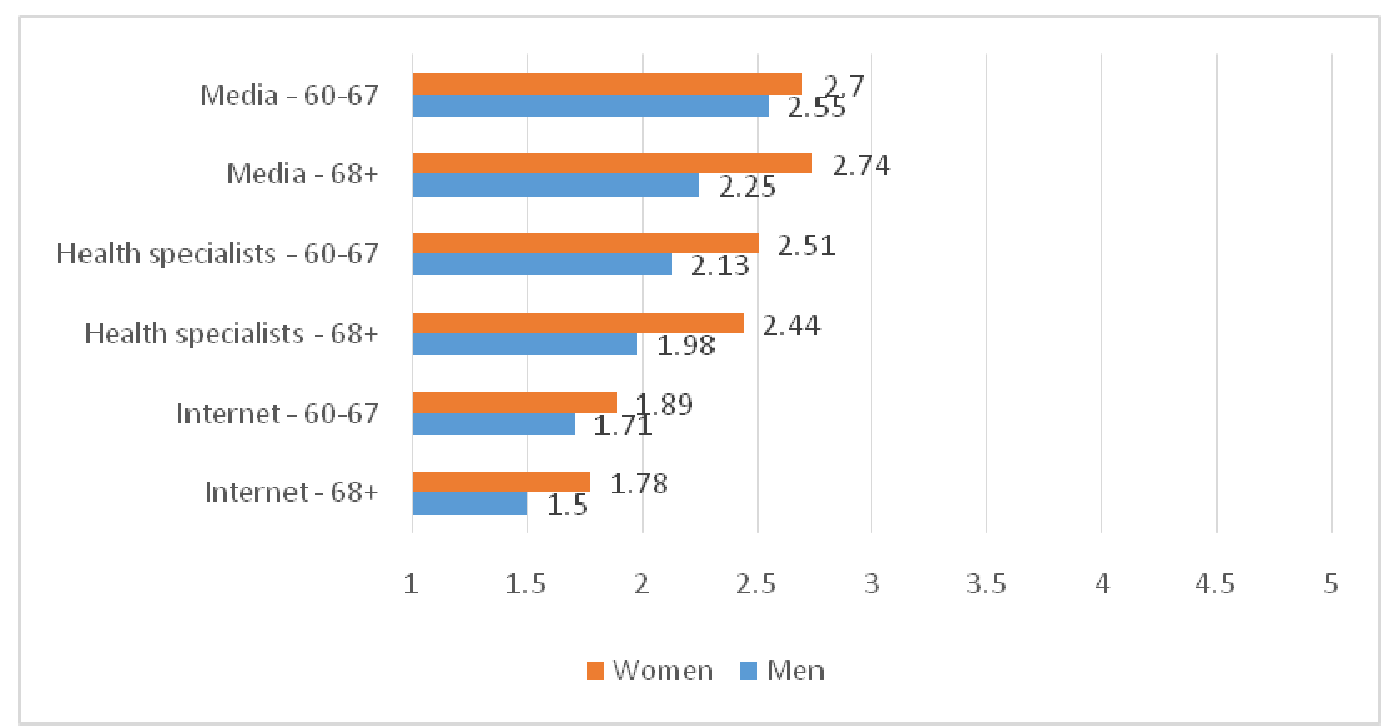

Figure 5. Purposive information seeking - Difference by sex and age

Figure 5 shows that women in both age groups sought information on purpose more frequently than men. In the younger group women sought information significantly more often than men from Health specialists $\mathrm{F}(1,89=4,465 ; \mathrm{p}=0,037)$. The difference by sex was not significant for Media $\mathrm{F}(1,85=0,444 ; \mathrm{p}=0,507)$ and the Internet $\mathrm{F}(1,90=1,037 ; \mathrm{p}=0,311)$. In the older age group, women sought information significantly more often then men in Media $F(1,85=4,459 ; p=0,038)$ and from Health specialists $\mathrm{F}(1,89=2,797 ; \mathrm{p}=0,015)$, while the difference for the Internet $\mathrm{F}$ $(1,89=2,797 ; \mathrm{p}=0,098)$ was not significant. 


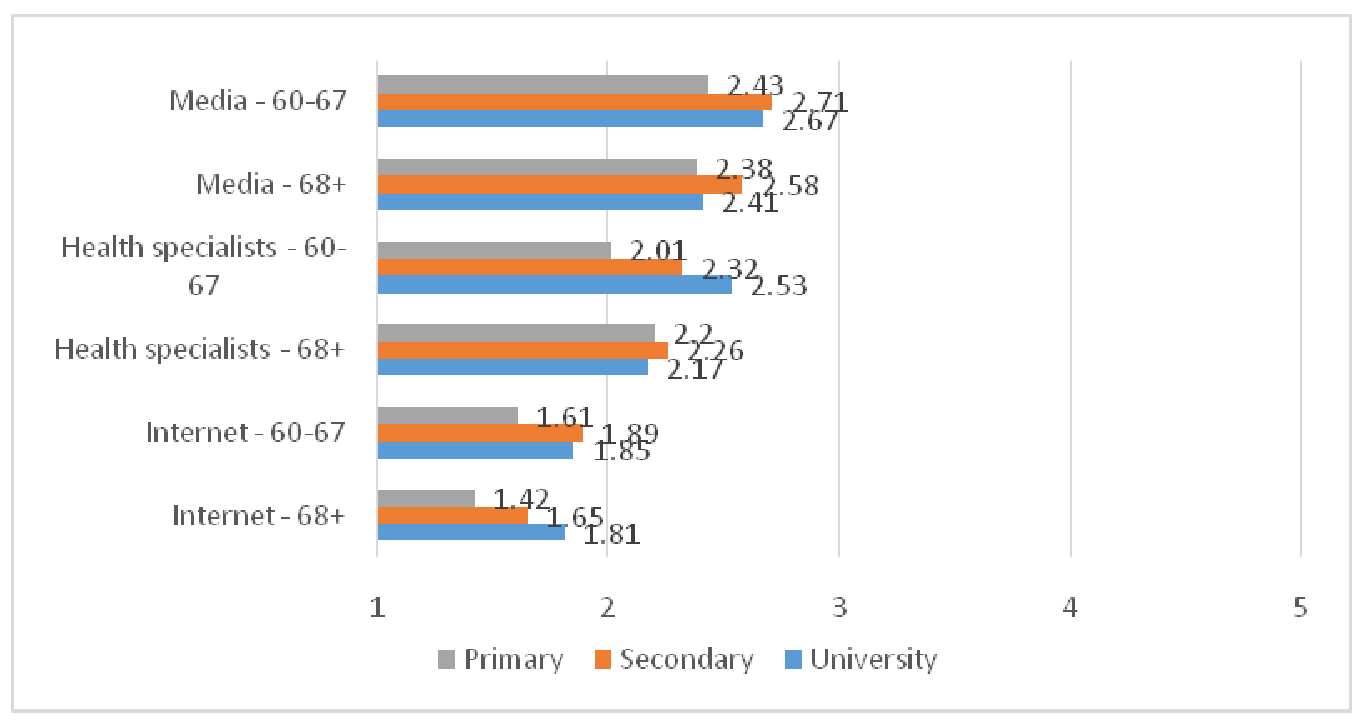

Figure 6. Purposive information seeking - Difference by education and age

An examination of how education and age interacted on purposive seeking revealed slight differences by educational groups (Figure 6). Those who have primary education tend to seek information less often than those who have secondary and university education, particularly on the Internet. However, no significant difference was found in the younger group, Media $F(2,77=0,366$; $\mathrm{p}=0,695)$, Health specialists $\mathrm{F}(2,82=1,985 ; \mathrm{p}=0,144)$, Internet $\mathrm{F}(2,82=0,613 ; \mathrm{p}=0,544)$, nor in the older group, Media $F(2,83=0,290 ; p=0,749$, Health specialists $F(2,87=0,070 ; p=0,933)$, Internet $F$ $(2,87=1,299 ; \mathrm{p}=0,278)$.

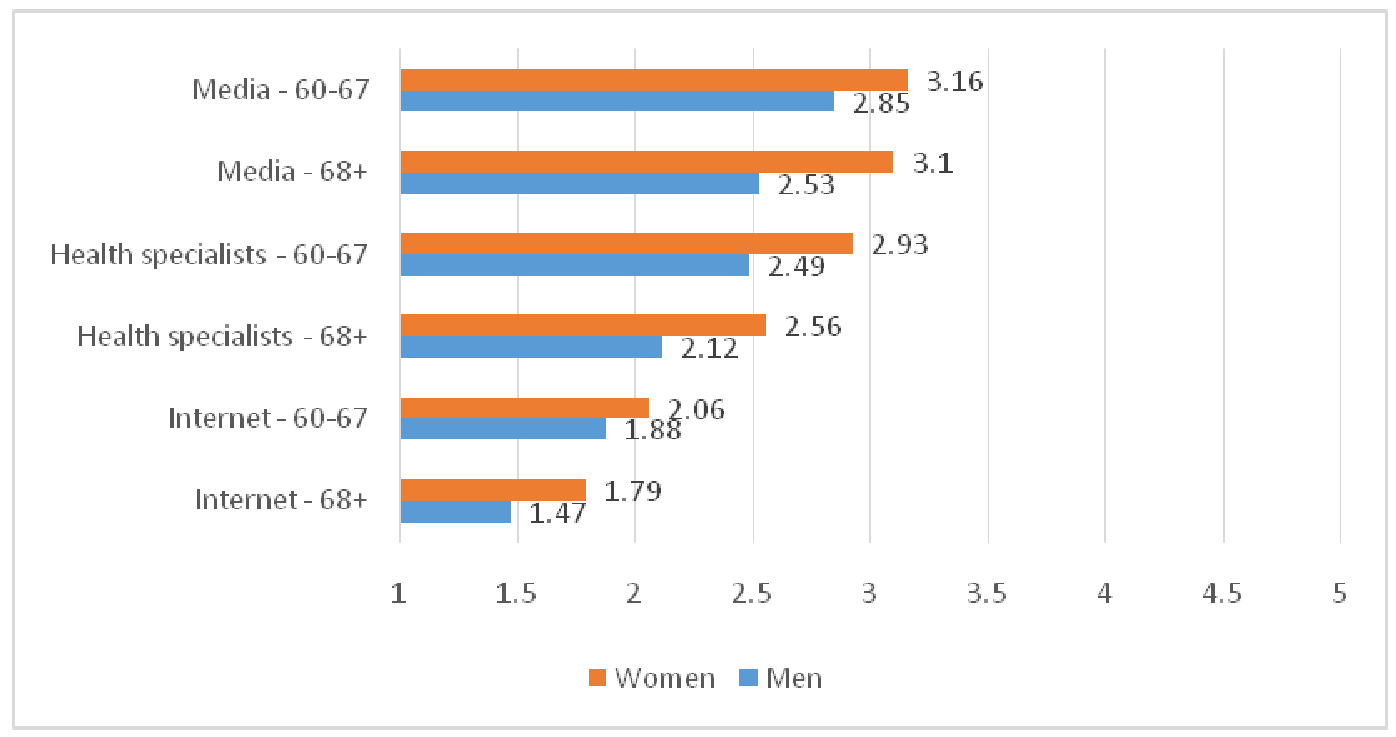

Figure 7. Opportunistic discovery of information - Difference by sex and age

Figure 7 shows that women discovered information opportunistically more frequently than men. Women in the younger group discovered information significantly more often from Health specialists $\mathrm{F}(1,84=4,494 ; \mathrm{p}=0,037)$ but difference by sex was not significant for Media $\mathrm{F}$ $(1,88=1,894 ; \mathrm{p}=0,172)$ and the Internet $\mathrm{F}(1,86=0,766 ; \mathrm{p}=0,384)$. In the older group, women discovered information significantly more often than men in Media $F(1,81=7,747 ; p=0,007)$ and from Health specialists $\mathrm{F}(1,78=3,839 ; \mathrm{p}=0,017)$, while the difference for the Internet was not significant $\mathrm{F}(1,83=3,823 ; \mathrm{p}=0,054)$. 


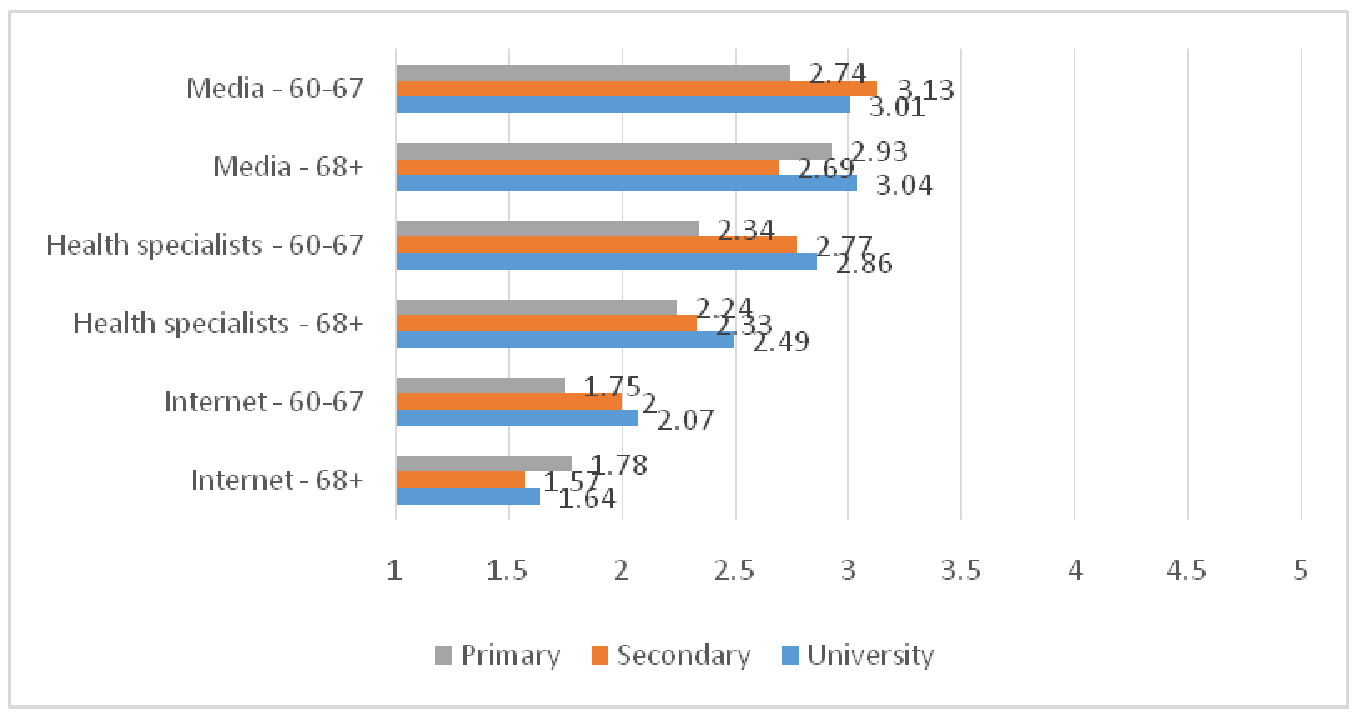

Figure 8. Opportunistic discovery of information - Difference by education and age

Although participants with primary education tend to discover information less often that those who are more educated, no significant results were revealed for the younger group, Media $\mathrm{F}$ $(2,82=0,695 ; \mathrm{p}=0,502)$, Health specialists $\mathrm{F}(2,79=1,692 ; \mathrm{p}=0,191)$, Internet $\mathrm{F}(2,80=0,582$; $\mathrm{p}=0,561)$, nor for the older group, Media $\mathrm{F}(2,79=0,965 ; \mathrm{p}=0,385)$, Health specialists $\mathrm{F}$ $(2,77=0,441 ; \mathrm{p}=0,645)$, Internet $\mathrm{F}(2,81=0,511 ; \mathrm{p}=0,602)$ (Figure 8$)$.

\subsection{Evaluation of the quality of information}

Evaluation of the quality of information was examined by asking about the usefulness and the reliability of the information. Results will be presented in the same sequence as for information seeking.

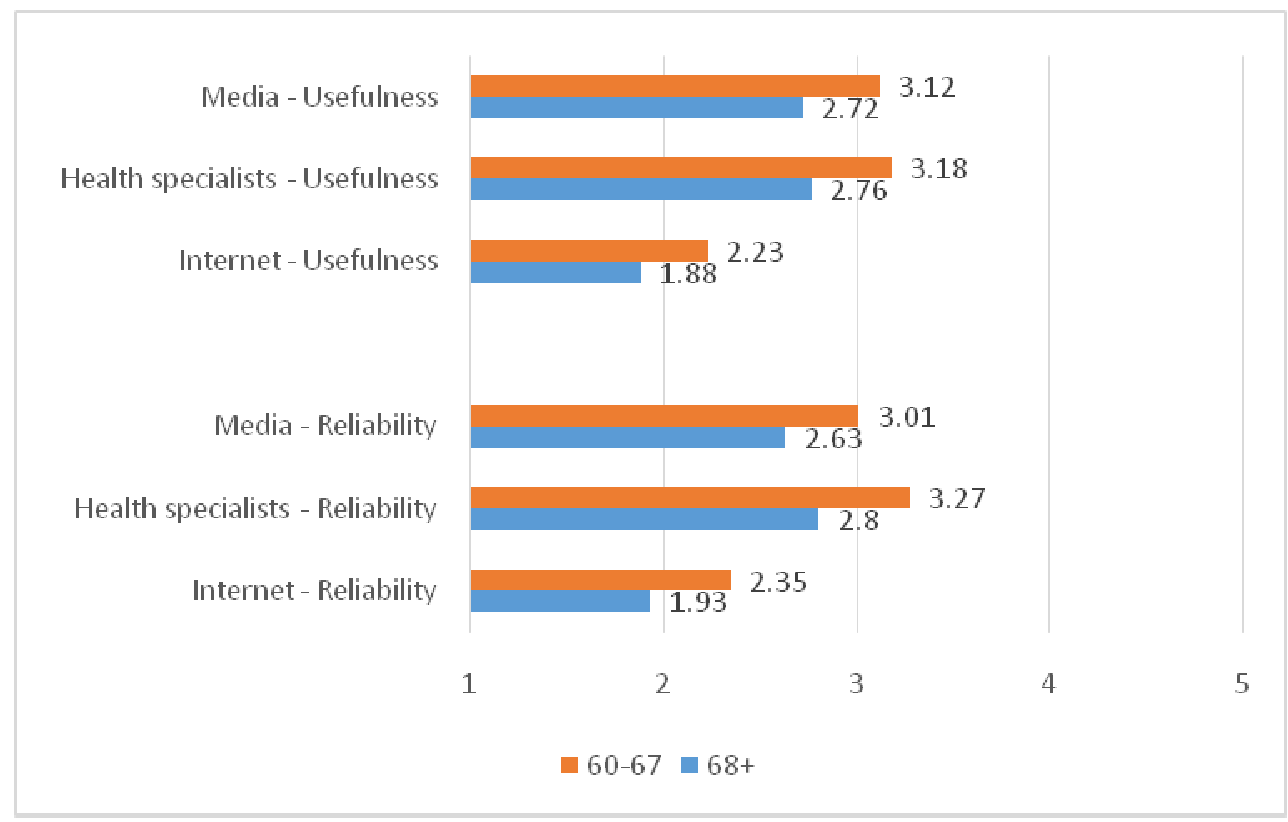

Figure 9. Usefulness and reliability of information - Difference by age

As can be seen in Figure 9, both age groups considered information on the Internet to be less useful and less reliable than information in Media and from Health specialist. The younger age group considered the usefulness of information in Media $F(1,176=6,29 ; p=0,013)$, from Health specialists $F(1,172=6,18 ; p=0,014)$, and on the Internet $F(1,167=4,37 ; p=0,038)$, to be significantly 
higher than the older group. Likewise, the younger group considered the reliability of information in Media $\mathrm{F}(1,168=5,47 ; \mathrm{p}=0,021)$, from Health specialists $\mathrm{F}(1,168=7,49 ; \mathrm{p}=0,007)$, and on the Internet $\mathrm{F}(1,168=8,87 ; \mathrm{p}=0,003)$, to be significantly higher than the older age group.

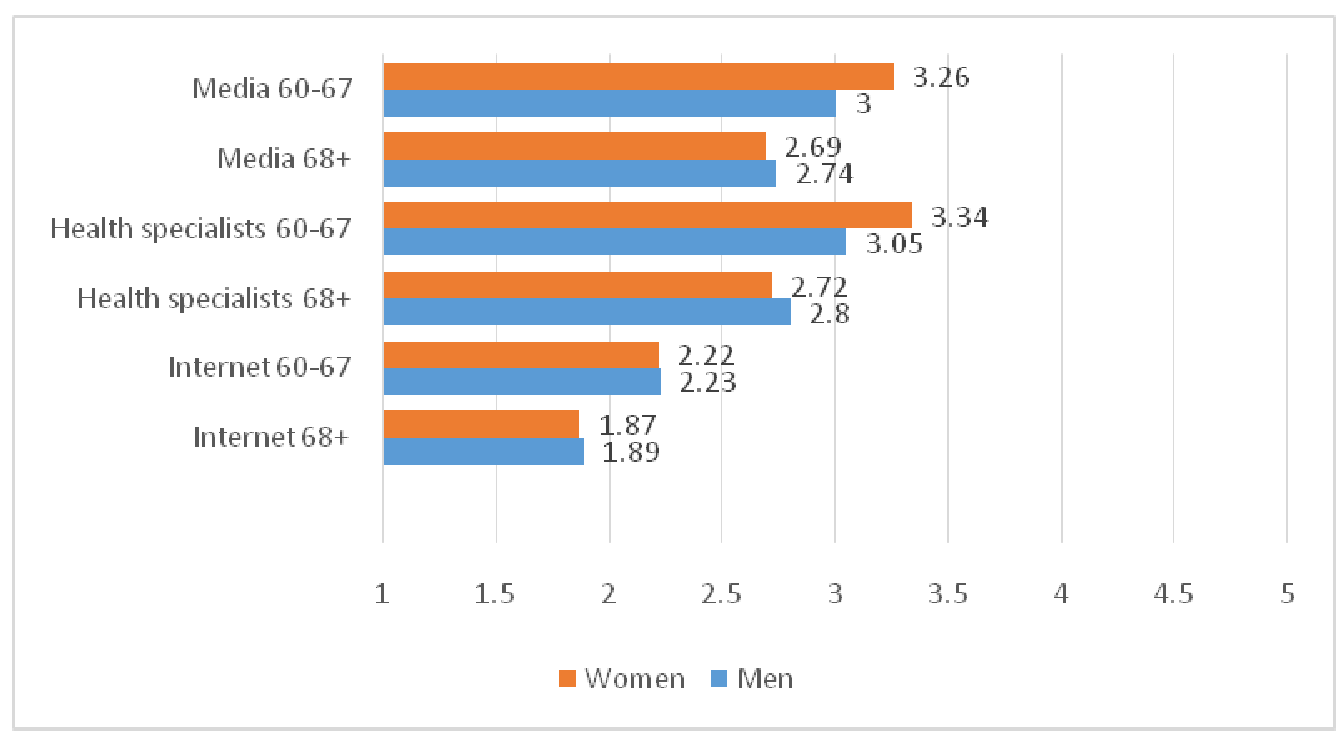

Figure 10. Usefulness of information - Difference by sex and age

Figure 10 shows that apart from women in the younger age group, who considered information in Media and from Health specialists to be somewhat more useful than men, the evaluation of the channels was identical for men and women. In both the younger and older group respectively, there was no significant difference for evaluation of information in Media, $\mathrm{F}(1,87=1,32 ; \mathrm{p}=0,254)$; $\mathrm{F}(1,87=0,04 ; p=0,84)$, from Health specialists $\mathrm{F}(1,84=1,49 ; \mathrm{p}=0,225) ; \mathrm{F}(1,86=0,11 ; p=0,736)$, and on the Internet $F(1,79=0 ; p=0,969) ; F(1,86=0,01 ; p=0,908)$.

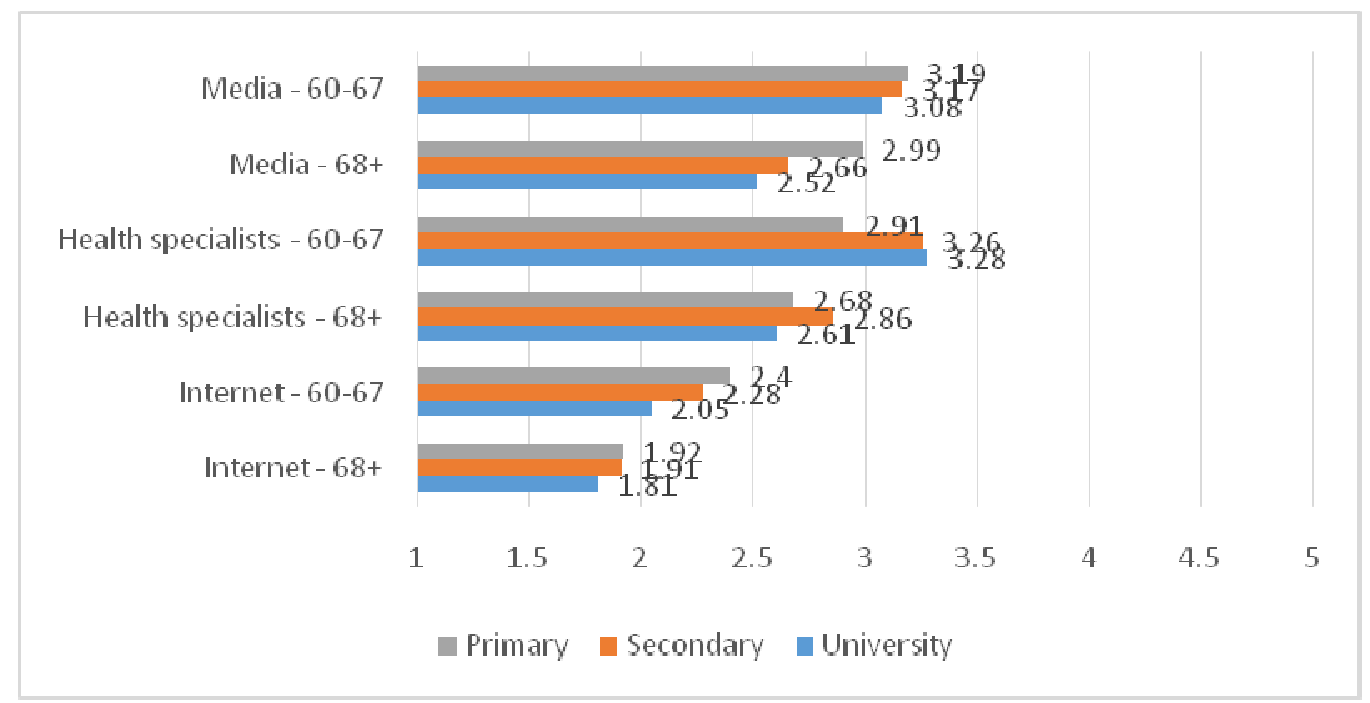

Figure 11. Usefulness of information - Difference by education and age

Figure 11, shows that all educational groups, in both age groups, consider information on the Internet to be least useful. Furthermore, those who have university education, in both age groups, consider information in all channels to be somewhat less useful than those who have primary and secondary education. However, in both the younger and older group respectively, the difference was not significant for Media, $\mathrm{F}(2,80=0,09 ; \mathrm{p}=0,916) ; \mathrm{F}(2,85=1,16 ; \mathrm{p}=0,319)$, Health specialists, $\mathrm{F}$ $(2,77=0,67 ; \mathrm{p}=0,515) ; \mathrm{F}(2,84=0,4 ; \mathrm{p}=0,674)$, and the Internet, $\mathrm{F}(2,72=0,53 ; \mathrm{p}=0,593) ; \mathrm{F}$ $(2,84=0,08 ; \mathrm{p}=0,926)$. 


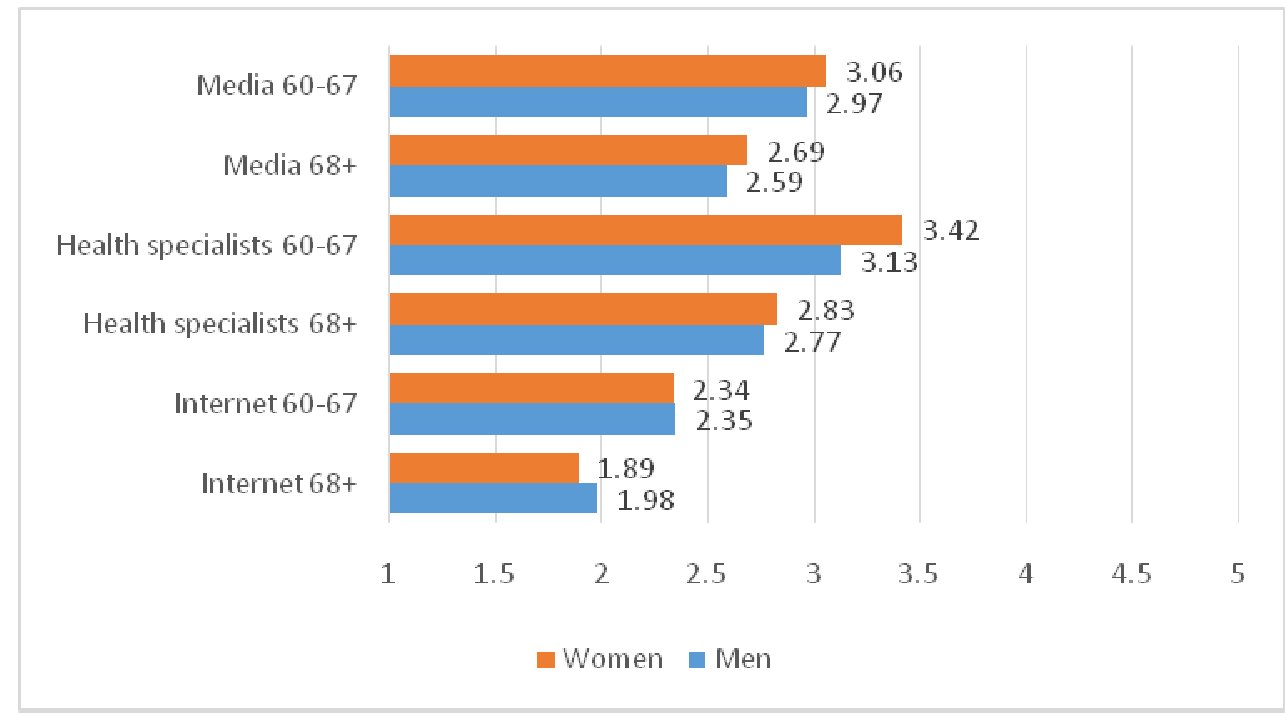

Figure 12. Reliability of information - Difference by sex and age

As can be seen in Figure 12, the evaluation of the reliability of information is in most cases almost identical for men and women. Furthermore, in both age groups, men and women considered information on the Internet to be least reliable, and information from Health specialists to be somewhat more reliable than information in Media. In both the younger and the older group respectively, there was no significant difference by sex for evaluation of the reliability of information in Media, $\mathrm{F}(1,80=0,15 ; \mathrm{p}=0,695) ; \mathrm{F}(1,86=0,2 ; \mathrm{p}=0,654)$, from Health specialists, $\mathrm{F}$ $(1,81=1,41 ; \mathrm{p}=0,239) ; \mathrm{F}(1,85=0,06 ; \mathrm{p}=0,814)$, and on the Internet, $\mathrm{F}(1,80=0 ; \mathrm{p}=0,955) ; \mathrm{F}$ $(1,86=0,3 ; \mathrm{p}=0,584)$.

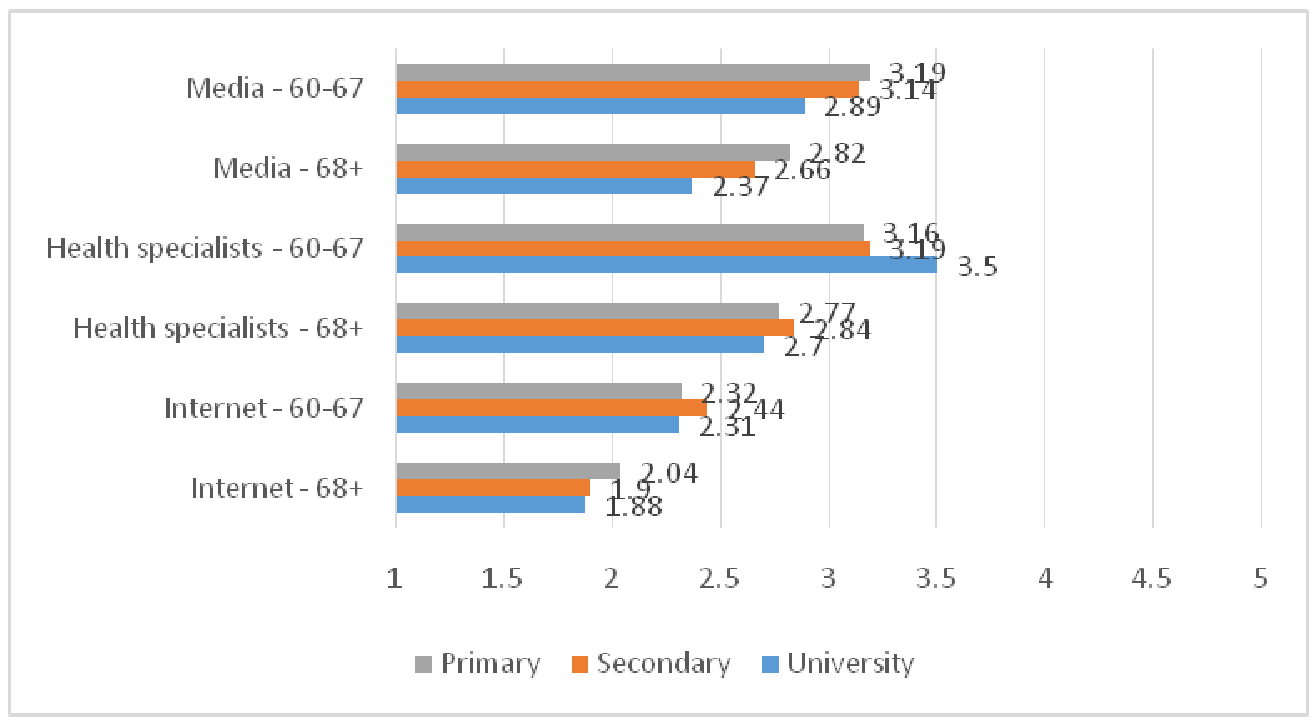

Figure 13. Reliability of information - Difference by education and age

Figure 13 shows that those who had university education, in both the younger, $\mathrm{F}(2,80=0,09$; $\mathrm{p}=0,916)$, and the older group, $\mathrm{F}(2,85=1,16 ; \mathrm{p}=0,319)$, evaluated information in Media as somewhat less reliable than those who had secondary and university education, although the difference was not significant. In the younger group, $\mathrm{F}(2,77=0,67 ; \mathrm{p}=0,515)$, participants with university education considered information from Health specialists to be somewhat more reliable than participants with primary and secondary education, while in the older group the evaluation was almost identical by educational groups, $\mathrm{F}(2,84=0,4 ; \mathrm{p}=0,674)$. For neither age group the difference was significant. For the Internet, the evaluation was almost identical and no significant difference found across educational groups, in both the younger $F(2,72=0,53 ; p=0,593)$ and the 
older group $\mathrm{F}(2,84=0,08 ; \mathrm{p}=0,926)$.

What all educational groups had in common, in both the younger and the older age group, was that information on the Internet were considered less reliable than information from Health specialists and in Media. Furthermore, participants with university education in both age groups found information from Health specialists to be somewhat more reliable than information in Media.

\section{Discussion}

Senior citizens form the fastest growing group both in western societies and many other parts of the world (United Nations, 2013). It is vital to optimise their opportunities to remain in control of their lives, as independent and active participants of the community. Otherwise, they may be faced with social exclusion (Walsh, Scharf and Keating, 2016, p. 1-3) and as a consequence a diminished quality of life. Enhancing their prospects of enjoying good health for as long as possible not only supports their chances of maintaining autonomy and wellness but can also help reduce prejudice against seniors.

The current study examined various aspects of MHIL among Icelanders aged 60 years or older. Instead of classifying all seniors in one age category, as quantitative studies often do, the study aimed at investigating similarities and differences among them. This was done by comparing results about two age groups, people 60 to 67 years old and those who are 68 years or older. In addition, the study explored the effects of sex and education for each group.

Motivation to acquire knowledge about healthy living is one of the key elements of MHIL (UNESCO, 2014; World Health Organization, 1998). In particular, interest in healthy behaviour has been recognized as an important factor (Eriksson-Backa, Ek, Niemelä and Huotari, 2012, p. 88). Although the age groups were found to be similarly motivated, results about sex and education revealed some differences. In the younger group, men and people with primary education were somewhat less interested. In both age groups, men were inclined to discuss the topic less frequently than women and those with primary education less often than people with more education. None of these differences were statistically significant but the findings nevertheless stress the importance of giving special attention to men and people with the lowest level of education.

The findings about information seeking revealed both similarities and differences across the age groups. Contradictory to what studies have sometimes reported, that seniors differ in source preference by age (Suri, Chang and Foo, 2014, p. 130), both groups sought information most often in the Media and least often on the Internet. In addition, both age groups favoured the same way of information seeking, as they discovered information opportunistically more often than they sought it on purpose. Results about the frequency of information seeking, on the other hand, showed some dissimilarities across the age groups. The main difference was that the younger group discovered information from Health specialists and on the Internet significantly more frequently than the older group. Results about purposive seeking, however, revealed that the younger group sought information only slightly more often in all information channels than the older group. Although this is similar to findings from other studies (Suri, Chang and Foo, 2014, p. 130), it needs to be kept in mind that the difference for purposive seeking across the age groups was very small and not significant.

Previous studies have reported women to be more likely to seek information about health than men (Pálsdóttir, 2008; Suri, Chang and Foo, 2014, p. 130). The results are in line with this, as women sought information more frequently than men. Nevertheless, significant difference was not detected for all channels. It has also been noted that the more educated people are, the more likely they are to engage in purposive health information seeking (O'Keefe, Boyd and Brown, 1998, p. 33; Pálsdóttir, 2008). Although the results here show that participants with primary education tend 
to seek information somewhat less often that those who are more educated, no significant difference was revealed across the age groups.

Evaluation of the quality of information is an important aspect of MHIL. In the past years the discussion has centred on the Internet, with health specialists raising concerns (Bedell et al., 2004, p. 692; Cline and Haynes, 2001, p. 682). Prior studies show that people consider information on the Internet to be less important than information by health specialists (Marshall and Williams, 2006, p. 150; Pálsdóttir, 2011). However, findings also indicate that the perceived importance of online health information is growing, particularly in countries that have high Internet usage (Kummervold et al., 2008; Pálsdóttir, 2011).

Relatively little is though known about how senior citizens evaluate health information in different information sources or channels. The results of the study show that the older age group was significantly more critical of information in all channels than those who are younger. What the age groups, however, had in common was that they found information on the Internet to be less useful and reliable, than information in Media and from Health specialist. An examination of the effects of sex and education further supported this finding, as men and women in both age groups, as well as all educational groups in both age groups, considered information on the Internet to be least useful and least reliable.

The overall study is limited by a rather low response rate of $58.4 \%$. This is considered satisfactory in a survey but nevertheless raises the question, whether or not those who answered are giving a biased picture of those who did not respond. Nevertheless, the study results may provide valuable information about the MHIL of the senior citizens.

\section{Conclusion}

It is of major significance to support and enhance senior citizens possibilities to remain healthy and active members of society, for as long as possible. A necessary prerequisite for this is that they maintain their understanding of healthy living. Competency in MHIL is important as a tool for lifelong learning, as it provides people with better opportunities to make informed health decisions. The MHIL calls for a dynamic and multi-level information behaviours. As seniors move through their life course they are constantly required to adjust to and learn about recent advances in their information environment. Otherwise they are faced with constrained opportunities at developing their knowledge and the risk of old-age exclusion.

Studies have sometimes described older people as being less competent and active at gathering new knowledge than those who are younger. Furthermore, aspects of MHIL are often examined by using a relatively small set of information sources, in the past years mainly digital sources, where senior citizens are assessed against the younger age groups. By comparing two groups of seniors who are relatively close in age, and by investigating their information seeking behaviour and judgement of information quality within a broad network of information sources in different channels, the current study sought to provide a more holistic picture of their MHIL skills.

Taken together, the results suggest that senior citizens at the age 68 years and older have more in common with those who belong to the age group 60 to 67 years, than what separates them. Both age groups were equally motivated towards health information seeking. Likewise, both groups had the same preferences for ways of information seeking and information channels, as well as holding the same beliefs about the quality of information in the different channels. The main differences was that the younger group sought information somewhat more frequently than the older, however, the dissimilarities were small and only significant for opportunistic discovery of information. In addition, the older group was more critical in the evaluation of information in all channels than the younger group.

By concentrating on the senior citizens strengths at MHIL, rather than their perceived weaknesses, 
health authorities, libraries and information professionals together may be better equipped at enhancing their possibilities to enjoy good health, independence and quality of life.

\section{References}

Bedell, S. E., Agrawal, A. and Petersen, L. E. (2004) A Systematic Critique of Diabetes on the World Wide Web for Patients and their Physicians, International Journal of Health Informatics, 73(9-10), pp. 687-694, available: http://dx.doi.org/10.1016/j.ijmedinf.2004.04.011 [accessed 16 November 2017].

Buttriss, J. L. (1997) Food and Nutrition: Attitudes, Beliefs, and Knowledge in the United Kingdom, American Journal of Clinical Nutrition, 65, pp. 1985S-1995S.

Cline, R. J. W. and Haynes, K. M. (2001) Consumer Health Information Seeking on the Internet: The State of the Art, Health Education Research, 16(6), pp. 671-692.

Enwald, H. et al. (2016) Everyday Health Information Literacy Among Young Men Compared with Adults with High Risk for Metabolic Syndrome: A Cross Sectional Population Based Study, Journal of Information Science, 42(3), pp. 344-355.

Erdelez, S. (1997) Information Encountering: A Conceptual Framework for Accidental Information Discovery, in Vakkari, P. et al. (eds.) Information Seeking in Context: Proceedings of an International Conference on Research in Information Needs, Seeking and Use in Different Contexts, 14-16 August, 1996 Tampere, Finland, London: Taylor Graham, pp. 412-421.

Eriksson-Backa, K., Ek, S., Niemelä, R. and Huotari, M-L. (2012) Health Information Literacy in Everyday Life: A Study of Finns Aged 65-79 Years; Health Informatics Journal, 8(2), pp. 83-94.

Foster, A. and Ford, N. (2003) Serendipity and Information Seeking: An Empirical Study, Journal of Documentation, 59(3), pp. 321-340, available: http://dx.doi.org/10.1108/00220410310472518 [accessed 16 November 2017].

Hesse, B. W. et al. (2005) Trust and Sources of Health Information: The Impact of the Internet and its Implications for Health Care Providers: Findings from the First Health Information National Trends Survey, JAMA Internal Medicine, 165(22), pp. 2618-2624.

Johnson, D. J. and Meischke, H.A. (1993) Comprehensive Model of Cancer-Related Information Seeking Applied to Magazines, Human Communication Research, 19(3), pp. 343-367.

Kummervold, P. E. et al. (2008). eHealth Trends in Europe 2005-2007: A Population-Based Survey, Journal of Medical Internet Research, 10(4), e42, available: https:// www.ncbi.nlm.nih.gov/pmc/articles/PMC2629359/ [accessed 16 November 2017].

Lög um málefni aldraðra nr. 125/1999 [Act on the Affairs of the Elderly].

Marshall, L. A. and Williams, D. (2006) Health Information: Does Quality Count for the Consumer? How consumers Evaluate the Quality of Health Information Materials Across a Variety of Media, Journal of Librarianship and Information Science, 38(3), pp. 141-156.

McKenzie, P. J. (2003) A Model of Information Practices in Accounts of Everyday-Life Information Seeking, Journal of Documentation, 59(1), pp. 19-40.

Niemelä, R., Ek, S., Erkisson-Backa, K. and Huotari, M.-L. (2012) A Screening Tool for Assessing Everyday Health Information Literacy, Libri, Vol. 62, pp.125-134. 
O'Keefe, G. J., Boyd, H. H. and Brown, M. R. (1998) Who Learns Preventive Health Care Information from Where: Cross-Channel and Repertoire Comparisons, Health Communication, 10 (1), pp.25-36.

Pálsdóttir, A. (2008) Information Behaviour, Health Self-Efficacy Beliefs and Health Behaviour in Icelanders' Everyday Life, Information Research, 13(1), paper 334, available: http:// InformationR.net/ir/13-1/paper334.html [accessed 16 November 2017].

Pálsdóttir, A. (2009) Seeking Information About Health and Lifestyle on the Internet, Information Research, 14(1), paper 389, available: http://InformationR.net/ir/14-1/paper389.html [accessed 16 November 2017].

Pálsdóttir, A. (2010) The Connection Between Purposive Information Seeking and Information Encountering: A study of Icelanders' Health and Lifestyle Information Seeking, Journal of Documentation, 66(2), pp. 224-244, available: http://dx.doi.org/10.1108/00220411011023634 [accessed 16 November 2017].

Pálsdóttir, A. (2011) Icelanders and Trust on the Internet as a Source of Health and Lifestyle Information, Information Research, 16(1), paper 470, available: http://InformationR.net/ir/16-1/ paper470.html [accessed 16 November 2017].

Ries, W. and Pöthiga, D. (1984) Chronological and Biological Age, Experimental Gerontology, 19 (3), pp. 211-216.

Savolainen, R. (2015) Cognitive Barriers to Information Seeking: A Conceptual Analysis, Journal of Information Science, 41(5), pp. 613-623.

Schardt, C. (2011) Health Information Literacy Meets Evidence-Based Practice, Journal of Medical Library Association, 99(1), pp.1-2.

Smith, A. (2014) Older Adults and Technology Use,available: http:// www.pewinternet.org/2014/04/03/older-adults-and-technology-use/ [accessed 16 November 2017].

Soederberg Miller, L. M.and Bell, R. A. (2012) Online Health Information Seeking: The Influence of Age, Information Trustworthiness, and Search Challenges, Journal of Aging and Health, 24(3), pp. 525-541.

Suri, V. R., Chang, Y-K, Majid, S. and Foo, S. (2014) Health Information Literacy of Senior Citizens: A Review,in Kurbanoğlu, S., Grassian, E., Mizrachi, D. et al. (eds.), Information Literacy: Lifelong Learning and Digital Citizenship in the $21^{\text {st }}$ Century, Communications in Computer and Information Science, 492, Heidelberg: Springer International Publishing,128-137.

Statistics Iceland (2012) Computer and Internet Usage by Individuals 2012, Statistical Series: Tourism, Transport and IT, 97(33), available: http://statice.is/publications/news-archive/scienceand-technology/computer-and-internet-usage-by-individuals-2012/ [accessed 16 November 2017].

Thane, P. (1989) History and the Sociology of Ageing, Social History of Medicine, 2(1), pp. 9396.

Toms, E. G. (2000) Serendipitous Information Retrieval, in Proceedings of the first DELOS network searching and querying in digital libraries, Zurich, Switzerland, available: http:// www.ercim.org/publication/ws-proceedings/DelNoe01/3_Toms.pdf [accessed 16 November 2017]. 
UNESCO (2014) Media and Information Literacy, available: http://www.unesco.org/new/en/ communication-and-information/capacity-building-tools/media-and-information-literacy/ [accessed 16 November 2017].

United Nations (2013). World Population Aging, available: , http://www.un.org/en/development/ desa/population/publications/pdf/ageing/WorldPopulationAgeing2013.pd f [accessed 16 November 2017].

Walsh, K., Scharf, T.and Keating, N. (2016) Social Exclusion of Older Persons: A Scoping Review and Conceptual Framework, European Journal of Ageing, 14, pp. 81-98, available: https:// link.springer.com/content/pdf/10.1007\%2Fs10433-016-0398-8.pdf [accessed 16 November 2017].

Wilson, T. D. (2000) Information Behaviour, Informing Science, 3(2), pp. 49-55, available: http:// inform.nu/Articles/Vol3/v3n2p49-56.pdf [accessed 16 November 2017].

World Health Organization (1998) Health Promotion Glossary, available: http://www.who.int/ healthpromotion/about/HPR\%20Glossary\%201998.pdf?ua=1 [accessed 16 November 2017].

World Health Organization (2007) Global Age Friendly Cities: A Guide, Geneva: World Health Organization, available: http://www.who.int/ageing/publications/

Global_age_friendly_cities_Guide_English.pdf [accessed 16 November 2017]. 